\title{
Research on the optimization of management model in large-scale enterprises
}

\author{
Qian Zhang ${ }^{* 1, a},{ }$ ie Li $^{2, b}$ \\ ${ }^{1}$ State Grid Energy Research Institute Company Limited Beijing, China \\ ${ }^{2}$ Beijing Electric Power Corporation Beijing, China
}

\begin{abstract}
The management model is a strategic and systematic project related on the construction of the enterprise's core competitiveness. As the pillars of the economy and people's livelihood and the national lifeline, how to build a management model that meets the company's own development stage and long-term strategic needs is the primary task facing enterprises to promote the reform of the group management system.
\end{abstract}

\section{Basic understanding of group management and control}

According to the theory of group management and control, the conglomerate management and control mode is usually divided into three types: financial, strategic and operational management and control.

Financial management and control is a management and control model that maximizes the decentralization of enterprises. The main feature of this model is that the headquarters plays the role of financial investor, and the conglomerate realizes investment portfolio and risk diversification. Under this management and control model, the functions of the conglomerate's headquarters mainly include asset operations, risk management and investment evaluation etc. Group subsidiaries can develop their own business development strategies, business competition strategies and business plans, and operate independently. They only need to reach the financial goals of headquarters approval every year.

Strategic management and control belongs to a relatively centralized management and control model. The main feature of this model is that the headquarters plays the role of strategic manager, and the group realizes diversified industry coordination and scope economy. Under this management and control model, the functions of the headquarters include formulating development goals, clarifying investment plans, and operating guidance etc. The subsidiary is responsible for implementing the group strategic plan and completing the tasks assigned by the headquarters.

Operational management and control is the most centralized type of conglomerate management and control model. The main feature of this model is that the headquarters plays the role of a full-scale manager, and the group realizes business integration and economies of scale Under this management and control model, the management functions undertaken by the headquarters of the group cover the each fields of setting strategic objectives, the implementation of annual plans, performance evaluation, control operations, and manpower management etc. The headquarters exercises direct and in-depth management control over the business operations of the subsidiaries.

Due to the complexity of the actual situation, group companies usually adopt two or more of the previous three control modes to form a hybrid management and control mode, which has two manifestations pattern: one is vertical mixing, the group headquarters adopts a certain control mode for the subsidiary companies, while the subsidiary adopts another control mode for its subordinate units; the second is horizontal mixing, according to the subsidiary's business characteristics, development stage, strategic position, property rights relationship, etc., the headquarters adopts different control modes. In recent years, state-owned enterprises such as China Oil \& Foodstuffs Corporation, Sinochem Group and PetroChina have adopted a similar "strategy finance" management and control model in light of the central reform requirements and themselves diversified business characteristics. They had an active exploration in terms of optimize the management and control mode of the group, enhance the vitality of grassroots enterprises, and improve the capital operation ability and other aspects, which provided experience reference for other large enterprises to optimize group management and control.

\section{Practice of "Strategy Finance" Group Control Mode of The Central Enterprises}

\subsection{China Oil \& Foodstuffs Corporation (COFCO)}

COFCO is the first batch of state-owned capital investment companies to be piloted by the State-owned Assets Supervision and Administration Commission. Except for its subordinate professional companies, the

\footnotetext{
$\mathrm{a}^{*}$ Corresponding author e-mail: zhangqian881111@163.com

be-mail: lijie@bj.sgcc.com.cn
} 
Group has not set up investment companies anymore, and has mainly relied on the positioning of state-owned capital investment companies to carry out a series of management changes.

\subsubsection{Implement differentiated equity structure design:}

Classification of layered to promote mixed ownership and diversification of equity, magnify the function of stateowned capital, and increase the flexibility of business layout. COFCO actively introduces various types of capital at home and abroad, through mixed ownership reform to optimize the capital structure of the real estate business, improves profitability, serves the development of the main business, and at the same time through Layers of holding form to fully amplifies the function of stateowned capital; and through the combination of industry and finance to improve the ability of financial business serve the main business.

\subsubsection{Optimize the control structure:}

COFCO Headquarters implements the reform of the large department system, and integrates all functions of strategy, planning, projecting, investment, and assessment into the Group Strategy Department in accordance with the principle of "small headquarters and large industry" to achieve strategic closed-loop management. On this basis, COFCO separates capital operation from asset management operations and builds a three-level management structure of "Group Headquarters Capital Layer-Specialized Platform Asset Layer-Production Unit Executive Layer". Among them, the group headquarters is the capital operation center, which as an industrial investment platform, financing platform, and asset integration optimization platform, it is mainly responsible for the allocation and supervision of state-owned capital, manages the group's strategy and resource allocation, carries out capital investment and evaluation, and strengthens the asset layout and capital operation capabilities; Specialized companies are the core of asset operation entities and its asset operation directly managed by the Group. They formulate competitive strategies, are responsible for asset scheduling, allocation, and production operations, and perform unified management of functions such as resource allocation, financial capital, innovative research and development, and brand building, responsible for the profitable return of asset operations, and accept the group's budget and assessment; the production unit is the executive layer, responsible for the specific production and operation of the business, including raw material procurement, product production, sales, cost management, etc.

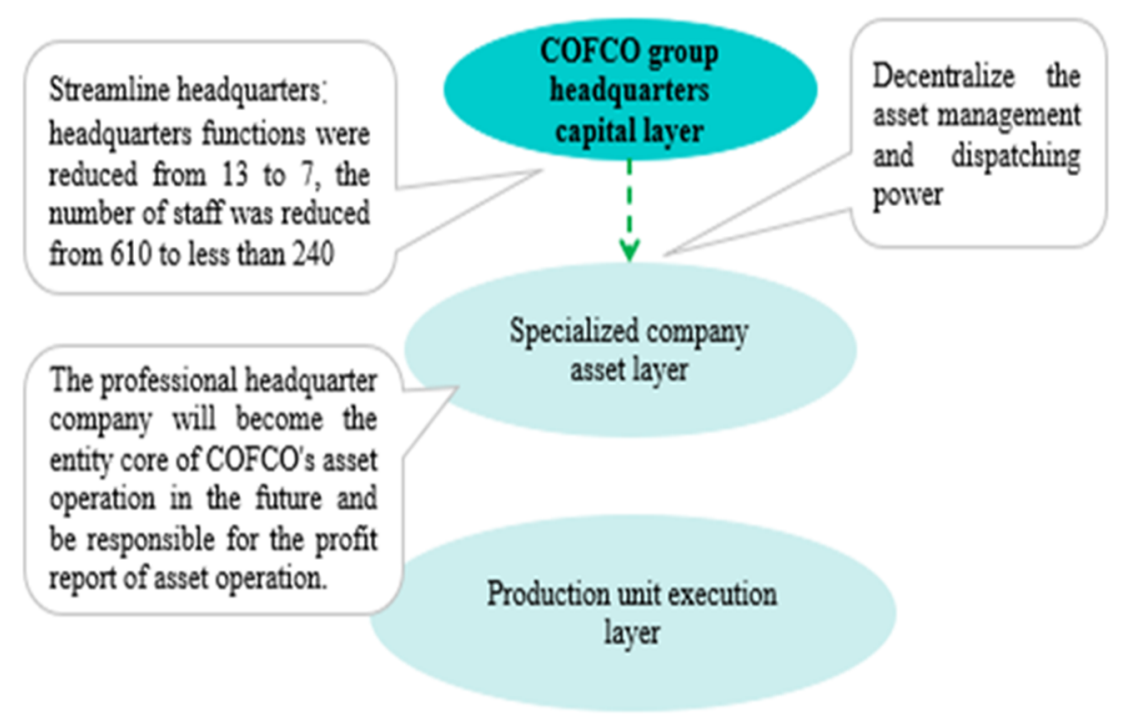

Fig 1. COFCO Management and control Structure

board of directors of the holding subsidiary has the power of independent supervision managers, including the independent selection of appointment, evaluation, and

\subsubsection{Improve corporate governance:}

COFCO's board of directors has four special committees: strategy committee, audit committee, remuneration and assessment committee and nomination committee. The board of directors of the headquarters is responsible for the formulation of macro strategies, the overall asset operation and capital management of the group. In terms of personnel recruiting and selecting, the board of directors of the headquarters has the right to select, evaluate and develop salary for the managers of the headquarters. The supervisory management personnel. The board of directors of the holding subsidiary shall regularly submit financial reports to the board of directors of the headquarters for supervision. Among them, the main functions of the board of directors of a listed company are to formulate strategies within the unit, as well as to make decisions on production, operation, marketing, and procurement etc., implement the strategic layout and corporate culture of the head office. 


\subsection{China National Petroleum Corporation}

CNPC is an important state-owned backbone enterprise and one of China's major oil and gas producers and suppliers. It is a comprehensive international energy company, which integrated oil and gas exploration and development, refining and chemical industry, sales and trade, pipeline storage and transportation, engineering technology, engineering construction, equipment manufacturing, and financial services. In the context of a sharp drop in oil prices and the gradual advancement of the market-oriented reform of the oil and gas system, CNPC officially launched the deepening reform of the group management.

\subsubsection{Implement classified control:}

Enterprises affiliated to CNPC include holding subsidiaries, wholly-owned companies, directly-owned companies, and joint-stock companies, and carry out differentiated management and control according to the different natures of the companies.

One is to implement straight-line functional management of directly-owned enterprises and whollyowned subsidiaries. The straight-line functional management and control mechanism highlights that it still maintains a direct form of administrative intervention when exercising management rights over its affiliated companies, directly controls and approves major issues of its affiliated companies, and its strategic intentions and plans are also issued to various subordinate companies by a form of a direct command.

The second is to implement the management and control method of co-existing linear function management and corporate governance of the invested company. Its basic feature is that linear function management is real and corporate governance is virtual.

The third is to implement control over the controlling subsidiaries and shareholding companies with external shareholders, which mainly follow standardized corporate governance procedures, and send full-time directors and supervisors to fulfill the rights of investors according to a certain process.

\subsubsection{Restructuring department functions:}

By reducing the division of department responsibilities, integrating the same and similar responsibilities dispersed in different departments, to strengthen work coordination and improve operational efficiency.

\subsection{Sinochem Group}

Sinochem Group is a leading Integrated operation enterprise, which integrated the petroleum and chemical industries, agricultural inputs (seeds, pesticides, fertilizers) and modern agricultural services enterprise, and has stronger influence in urban development and operation and non-bank financial fields. In recent years, Sinochem Group has unremittingly promoted strategic transformation and management reform, and has achieved sustained, healthy and rapid development of the enterprise.

\subsubsection{Optimize and adjust the functions of the headquarters:}

Focusing on the company's strategic objectives, Sinochem Group in line with the principle of "small headquarters and large business", and according to the positioning of the strategically controlled headquarters to adjust the power and responsibility relationship between the group headquarters and business division (operation unit). To reshape and optimize the functions of the group headquarters. The group headquarters focuses on core functions that include strategic budget management, financial capital policies, appointment and dismissal of important personnel, performance appraisal, audit compliance management, Party construction discipline inspection and supervision, as well as collaborative resource sharing, while retaining the right of approve about important and special matters, also from top to bottom Realize full coverage of supervision and inspection. 


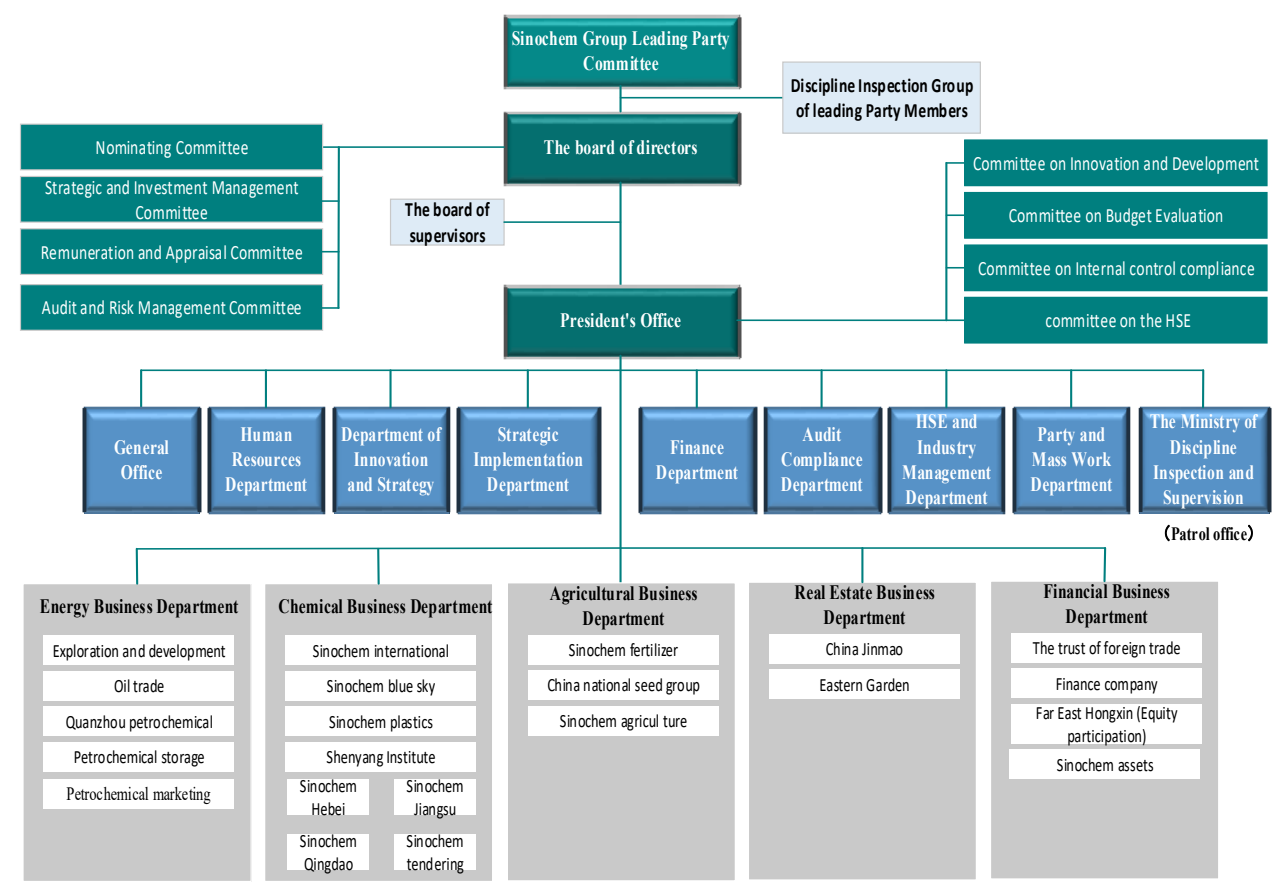

Fig 2. Organization structure diagram of Sinochem Group

\subsubsection{Reasonable authorization of five business divisions:}

Promote the merger and integration of diversified businesses, and set up five business divisions of energy, chemical, agriculture, real estate, and finance, which are directly managed by the group headquarters. The business department is positioned as the main body of operation management and control, and the headquarters vigorously streamlines the approval matters, fully giving the business department the authority of making strategic recommendations, operational decisions, selection and appointment, evaluation incentives, and major business investment decisions within the scope of authorization. Based on the principle of "management system is not scattered, responsibilities are not lost, and standards are not lowered", the headquarters delegate authority to undertake acceptance and system revision work.

\section{Enlightenment and reference}

First, focus on the selection of group management and control models based on the current corporate management and business characteristics. The above three national enterprise groups have adopted a similar "strategy finance" management and control model, straightened out the relationship of rights and responsibilities at all levels, adapt to the subsidiaries' the marketization and professionalization management needs, take the assets, the management, the management specialization as the core, Clearly define the functional orientation of management organizations at various levels, such as headquarters, platforms and enterprises, so to realize the effectively separate of capital operations and asset operations.

Second, clarify the function position of the headquarters, optimize the functions of the headquarters, and realize the efficient operation of the headquarters. Optimize the management functions of the headquarters, with the principles of streamlining and efficient, and better promote the strategic landing, optimize and adjust the related management functions, reduce the crossresponsibilities, break the department barriers, and promote work collaboration. Pay more attention on giving play to the headquarters' leading role in capital operation, strategic planning, and resource allocation.

Finally, continue to optimize the company's business structure and management structure to achieve differentiated management and control. Actively explore the management and control structure that suits the development of the Group, including the divisional model, platform company model, large-scale system, etc., and on this basis, carry out differentiated management and control of different business units according to different situations such as business importance and management capabilities.

\section{Conclusion}

It can be seen from the case that the group enterprise can establish a mixed mode of "platform company industrial fund" to establish a mixed industry management and control platform in the process of industrial system reform. Group enterprises can consider the following three structures. Introducing external industrial funds at the level of industrial control platform to promote the implementation of mixed ownership reform of industrial control platform. The industrial control platform will be regarded as a legal entity and operating entity, and the internal industrial development fund will be directly established. Give full play to the advantages of the parentsubsidiary fund structure of industrial funds and establish sub-funds in cooperation with external industrial funds. 


\section{Acknowledgment}

This work was supported by the science and technology project of State Grid Corporation of China (5400202016225A-0-0-00) - Research on typical application and technical economic evaluation of energy Internet in smart city.

\section{References}

1. Writing group of central Enterprise Management Promotion Activity Leading Group Office. Enterprise group control. Unity Press,2013.

2. Haolan Li, Shude Shi, Yong Zhang. Slim and fit to build strategic control headquarters. The enterprise management, 2018,18:64-66.

3. Wangang Bai. Group internal control based on management and control. China Development and Publication, 2009.

4. Lei Duan, Hongbo Zhang. Enterprise Group Management and control: Theory, Practice and Case study. China Development Press, 2009.

5. Chunyan Sun, Haichao Li. Identity Logic in the Management and control of state-owned Enterprises - A Case study of COFCO. Human resources development in China, 2016,10:15-21. 